\title{
Arsenic contamination in groundwater in Bangladesh: implications and challenges for healthcare policy
}

This article was published in the following Dove Press journal: Risk Management and Healthcare Policy

\author{
Sk Akhtar Ahmad' \\ Manzurul Haque Khan ${ }^{2}$ \\ Mushfiqul Haque ${ }^{2}$ \\ 'Department of Occupational and \\ Environmental Health, Bangladesh \\ University of Health Sciences, Mirpur, \\ Dhaka 1216, Bangladesh; ${ }^{2}$ Department \\ of Occupational and Environmental \\ Health, National Institute of \\ Preventive Medicine, Mohakhali, \\ Dhaka I2I2, Bangladesh
}

\begin{abstract}
Arsenic contamination of groundwater in Bangladesh has been recognized as a major public problem. The arsenic contamination was first identified in the tubewell water in 1993 in a northern district of Bangladesh. Tubewells are the main source of drinking water in rural areas, and except hilly and terrace upland throughout the Bangladesh, the arsenic-contaminated tubewells are distributed. Fifty million people of Bangladesh were estimated to be at risk of exposure to arsenic through consumption of water from contaminated tubewells. Chronic exposure to arsenic causes arsenicosis and may include multi-organ pathologies. Many of the health effects of chronic toxicity are evident in Bangladesh. Besides dermatological manifestations, noncommunicable diseases including cancer, adverse pregnancy outcomes, and decreased intelligence quotient among the children are reported to be increasing. Cancer due to long-term low-dose arsenic exposure through consumption of contaminated water is now an important concern of Bangladesh as it is being increasingly reported from arsenic-exposed individuals. Stoppage of consumption of the arsenic-contaminated water is the mainstay of arsenicosis prevention and case management. At present, a higher proportion of the people are still consuming arseniccontaminated water because of the lack of sustainable arsenic-safe water supply. In providing sustainable arsenic-safe water options, any option advocated should be cheap, easy to use, locally maintainable, and owned by the community. In addressing arsenic-related health issues, arsenic-exposed population needs to be brought under the coverage of the regular surveillance program for detection and subsequent management of noncommunicable diseases and cancers. Keywords: arsenic, arsenic contamination, ground water, tubewell, arsenicosis, Bangladesh
\end{abstract}

\section{Introduction}

Arsenic in groundwater is now a common phenomenon in many countries. The excess amount of arsenic in drinking water has been reported from various parts of the world, such as Argentina, Bangladesh, Chile, China, Hungary, India, Mexico, Nepal, Taiwan, and USA. WHO reported that at least 140 million people of 50 countries are exposed to arsenic through arsenic-contaminated groundwater at levels above $10 \mu \mathrm{g} / \mathrm{L}$ and a majority of them live in India and Bangladesh. ${ }^{1,2}$ In Bangladesh and India, the groundwater arsenic contamination initially emerged as a major health issue, and later came to be known as the worst arsenic-affected countries in the world in terms of population exposure to arsenic-contaminated water. The situation in Bangladesh so far is regarded as the biggest environmental arsenic poisoning, with about an estimated 50 million people being at risk of exposure. ${ }^{2-5}$ In 1993, Department of Public Health Engineering (DPHE), Bangladesh detected four tubewells in Chamagram village
Correspondence: Sk Akhtar Ahmad Bangladesh University of Health Sciences (BUHS), 125/I Darus Salam, Mirpur-I,

Dhaka 1216, Bangladesh

Tel +880 I55 2465730

Email anon@bdcom.com 
of Nawabganj district that yielded arsenic-contaminated groundwater, and in the following year, eight arsenicosis patients were identified in the same village. Soon after the detection of arsenic contamination in tubewell water, Bangladesh government with support from the national and international non-government organizations (NGOs) initiated a number of programs to determine the extent of arsenic contamination problem. ${ }^{5-7}$

Bangladesh is located on the largest deltaic land in the world and is largely a low-lying floodplain with about $75 \%$ of the land being less than three meters above the sea level. The Bay of Bengal lies to the south of Bangladesh with scattered hills in the eastern and northern parts. In Bangladesh, three large river systems, Ganges, Brahmaputra, and Meghna, with other 230 rivers and their tributaries form an intricate web in the country. Bangladesh has a total land area of 147,570 square kilometers with a population of about 158.9 million living mainly in rural-based settlements. ${ }^{8-11}$ Bangladesh is well known for both the surface and underground water sources. The people in Bangladesh, before the initiation of the tubewells, mainly relied on surface water sources like rivers, canals, lakes, ponds, and ringwells. Most of these water sources were microbiologically unsafe, and consequently, diarrheal diseases and cholera were widely prevalent. Groundwater tapped from only a few meters below the ground surface was considered to be microbiologically safe; this led to the temptation to initiate installation of tubewells with the aim of providing safe water for the population and thus reducing diarrheal diseases. Though the first tubewell installation scheme in this region was undertaken in $1928,{ }^{10-15}$ it took many decades to shift people from their traditional surface water to tubewell water in spite of intensive public campaign in favor of tubewells. Initially, people did not like tubewell water because of many traditional beliefs and perceptions. Important of those are unholy water, distaste, discoloration, etc. ${ }^{11,16}$ However, during the seventies, with mass awareness programs to change the people behaviors toward the use of tubewell water, there was a sharp increase of tubewell installation both by the public and private initiation. Ultimately, by nineties, $97 \%$ of the total population of Bangladesh had access to microbiologically safe drinking water through tubewells. The tubewell initiative, along with the awareness programs, was a great success in substantially bringing down the occurrence of diarrheal diseases and cholera, but unfortunately the discovery of arsenic contamination in the tubewell water and its health effects in the population leads to the reversal of the success story. ${ }^{11,13,14}$

\section{Sources of arsenic contamination}

Bangladesh is largely located on the Bengal Basin formed by the Ganga-Brahmaputra-Meghna (GBM) river system. This sedimentary basin has been formed by deposition of large volumes of arsenic-containing sediments that originated mainly from the Himalayas and was carried down by the mighty GBM rivers during the Pleistocene and Holocene periods. From these sediments, arsenic is leaching into the groundwater aquifers located in the fan deposit areas and Holocene alluvium. Though the exact mechanism of the arsenic leaching into groundwater is not clear, three mechanisms have been suggested in explaining the process of leaching of arsenic in the groundwater in GBM basin: 1) Arsenical pyrites in the alluvial sediments is oxidized and as a result arsenic is released into the groundwater. The oxidation might have occurred due to the entry of atmospheric oxygen into the aquifers subsequent to heavy withdrawal of ground water through shallow and deep tubewells. 2) Microbial metabolism of organic matter in the underground leading to anoxic conditions, thus leading to reduction of iron oxyhydroxides $(\mathrm{FeOOH})$, and subsequently resulting in the release of sorbed arsenic into the groundwater. 3) Arsenic anions sorbed to aquifer minerals are being displaced into solution by competitive exchange of phosphate anions resulting arsenic contamination in groundwater. The sources of phosphate are said to be the excessive use of phosphate fertilizer for agriculture, from fermentation or decay of buried peat deposits and other natural organic materials, etc. However, these suggested mechanisms yet remain to be substantiated. ${ }^{10,17-19}$

Groundwater in Bangladesh contains a higher concentration of arsenic than surface water sources and the groundwater contains both forms of inorganic arsenic (AsIII and AsV), and AsIII is the predominant species. In surface and dugwell water, both inorganic and organic forms are prevalent and the oxidized form of arsenic is the predominant species. Though both AsIII and AsV are toxic, AsIII has been reported to be the most toxic species. Arsenic contamination has been found more commonly in the tubewells which were installed within the depth of 15-50 m. However, in some areas, the arsenic contamination is found in the tubewells that were installed in greater depths. The arsenic contamination in the deep tubewell (DTWs; greater than $150 \mathrm{~m}$ deep) water is not common. Initially, the arsenic contamination in tubewell water of Bangladesh was thought to be in Gangetic delta plain; later, the contamination was detected in almost all the sedimentary areas of Bangladesh, except in Hilly and Pleistocene Uplands areas (Terrace Land). ${ }^{3,17,20}$ 


\section{Arsenic contamination situation}

In the year 1993, the water samples of some tubewells located in the northern bordering area of Bangladesh were examined for arsenic contamination and found to contain arsenic in the range of $0.059-0.388 \mathrm{mg} / \mathrm{L}$, which was higher than the Bangladesh standard level of arsenic in drinking water $(0.05 \mathrm{mg} / \mathrm{L}) .^{3,13,21-23}$ Within 12 years of the first detection of arsenic contamination, it was evident that arsenic contamination of groundwater was present in 62 out of 64 districts of Bangladesh. Following sporadic detection and reporting of arsenic contamination of groundwater, a countrywide screening for arsenic contamination in tubewell water was initiated in 1996. The initial screening that concluded in 1999 had tested 51,000 tubewells, which revealed that arsenic contamination was present in 211 out of 460 upazillas, which constituted about $29 \%$ of the tested tubewells. Subsequently, in 2003, a nationwide blanket survey was conducted by Bangladesh Arsenic Mitigation Water Supply Project (BAMWSP), covering 57,482 villages located in 271 upazillas, where it was reported that out of 4.95 million tubewells for arsenic contamination, 1.44 million tubewells were contaminated. The proportion of contamination was $29.1 \%$ which was similar to the initial screening. The nationwide screening further revealed that in $15 \%$ of the villages, more than $80 \%$ of the tubewells were contaminated, and these villages were assigned as "hot spots." The hot spots villages were more common in the middle and south parts of the country (Figure 1). The arsenic concentration in the water of the majority of the arsenic-contaminated tubewells was found to be in the range of $0.10-0.30 \mathrm{mg} / \mathrm{L}$. The highest concentration of arsenic detected in the tubewell water was $4.7 \mathrm{mg} / \mathrm{L}$. Another survey (2009) that sampled water from tubewells of 13,423 households throughout the country revealed that arsenic level in $12.6 \%$ of tested samples exceeded the Bangladesh arsenic standard for drinking water. ${ }^{3,13,23-25}$

\section{Exposure to arsenic and health impacts}

Arsenic is ubiquitous in nature, present in all environmental media and also in human bodies. Humans are routinely exposed to very small amounts of arsenic through food, water, and air.

However, in Bangladesh, groundwater is the main source of arsenic exposure; the population unknowingly receives substantial exposure to arsenic daily through the water they use for drinking and cooking. It has been reported that, on daily basis, a male living in arsenic-contaminated areas on an average ingests $1.734 \mathrm{mg}$ of arsenic through drinking water, while a female ingests $1.321 \mathrm{mg}$ of arsenic; they also receive additional exposure through vegetable and grains that they consume. ${ }^{26}$ People living in contaminated areas, per capita, daily average intake of arsenic was estimated to be $1017.9 \mu \mathrm{g}$, of which $54.3 \%$ was from rice and vegetables, and $45.7 \%$ was from drinking arsenic-contaminated water. Vegetables such as potato, pumpkin, amaranth leaf, and kalmi leaf from contaminated areas were found to contain a high concentration of arsenic; $27.9 \%$ arsenic in these vegetables was reported to be inorganic arsenic, while organic arsenic monomethylarsonic acid and dimethylarsinic acid was $21.5 \%$ and $50.6 \%$, respectively. ${ }^{27}$ The exposure through vegetables and grains becomes more complicated when the food is cooked or processed with arsenic-contaminated water. It is known that inorganic arsenic is more toxic to human health than organic arsenic, and the arsenic in groundwater of Bangladesh is predominantly inorganic. Exposure to arsenic may also occur through inhalation of polluted air, but such exposure in Bangladesh is less likely because there is no such industry which uses arsenic or emits arsenic into the atmosphere. Exposure to arsenic may lead to either acute or chronic toxicity; the amount of arsenic ingested through drinking contaminated tubewell water in Bangladesh is not sufficient to cause acute toxicity. Prolonged ingestion (2-10 years) of arsenic at levels found in tubewell water in Bangladesh may lead to the development of chronic toxicity. ${ }^{3,5,15,22,26}$

\section{Arsenicosis}

The illness that develops from chronic arsenic exposure is known as "Arsenicosis." Skin lesions such as melanosis, keratosis, and leucomelanosis are the characteristic manifestations of arsenicosis. In Bangladesh, these dermatological features are considered as the prime manifestations of arsenicosis. WHO defines arsenicosis as a "chronic condition arising from a prolonged ingestion of arsenic above safe dose for at least 6 months, usually manifested by characteristic skin lesions of melanosis and/or keratosis with or without involvement of internal organs." The safe dose of arsenic in drinking water in Bangladesh is $0.05 \mathrm{mg} / \mathrm{L} .{ }^{3,28}$ So far, in Bangladesh, no arsenicosis patients have been found among those who consumed tubewell water having the arsenic level lower than $0.082 \mathrm{mg} / \mathrm{L} .{ }^{29}$ Till 2012, a total of 65,910 arsenicosis cases had been identified in arsenic-contaminated areas of the country by Directorate General of Health Services of Bangladesh (DGHS). The arsenicosis patients were mostly identified by the house-to-house visits in the arsenic-affected areas by the health assistants of DGHS. Health assistants identified the suspected cases that were subsequently examined by medical officers at upazilla health complexes for confirmation. ${ }^{24}$ 


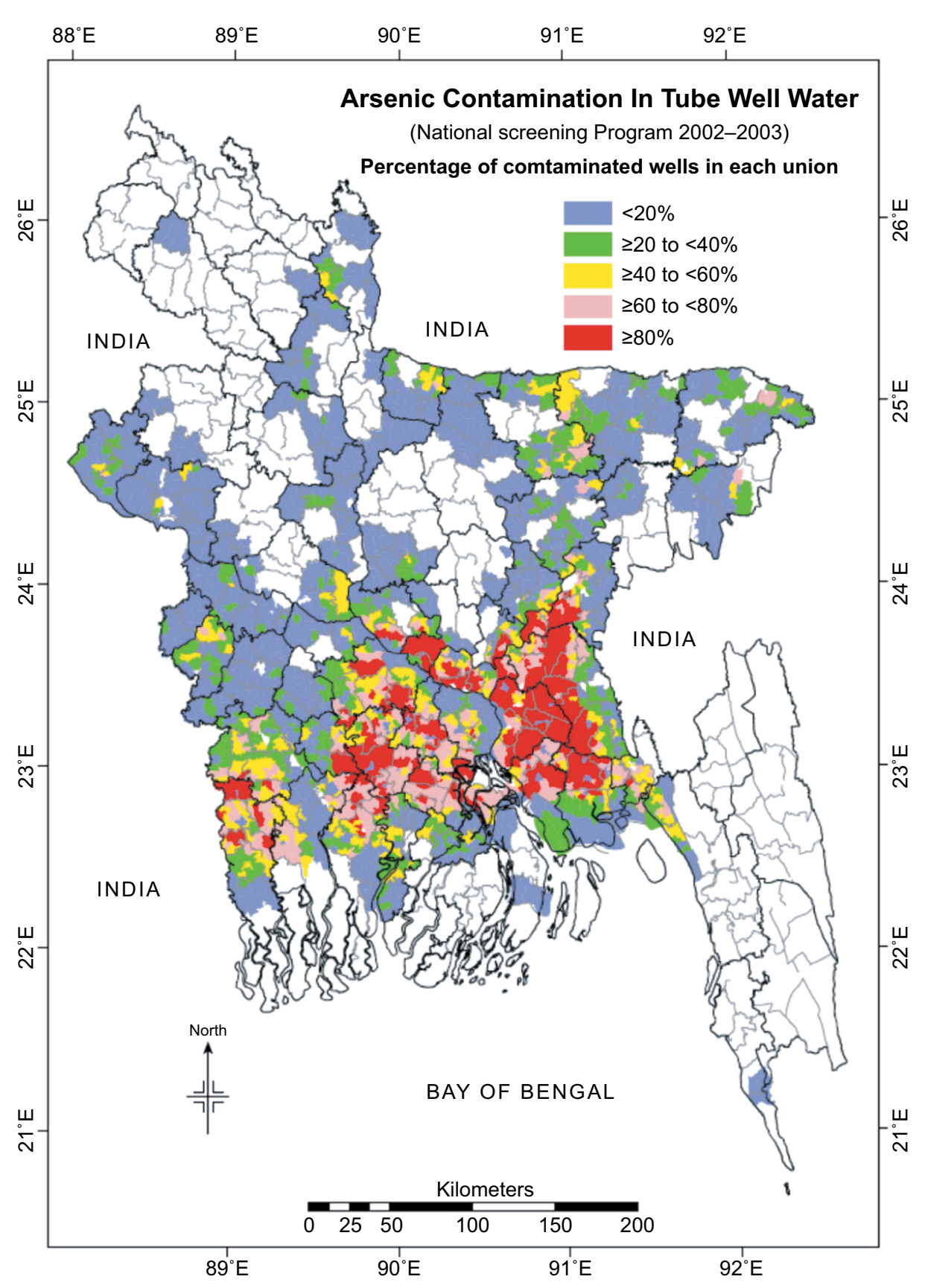

Figure I Arsenic contamination map of Bangladesh.

Source: National Arsenic Mitigation Information Center, BAMWSP.

Before initiation of the arsenicosis case identification activities, DGHS arranged training program mainly based on WHO field guide for all categories of health personnel including the medical officers to avoid underreporting of arsenicosis. ${ }^{23,28}$

Among the arsenicosis patients so far identified, a majority of them were found in rural areas and common among the young adults. Males are found to be more affected than females. Arsenicosis was found common among arsenicexposed population with poor socio-economic conditions.
Poor nutrition is also a common influencing factor for developing arsenicosis. People who take less protein are found to be more vulnerable to arsenic toxicity. Majority of arsenicosis patients in Bangladesh are in mild and moderate stages; severe arsenicosis was less frequently encountered. ${ }^{6,11,15,25}$ However, most of the severe arsenicosis patients are found to be associated with some complications, especially cancer. The common manifestations of arsenicosis reported in Bangladesh includes melanosis $(98.9 \%-100.0 \%)$, keratosis 
(58.8\%-92.7\%), leucomelanosis $(29.2 \%-42.7 \%)$, weakness (88.2\%-93.0\%), chronic cough $(20.0 \%-33.8 \%)$, conjunctival congestion $(9.4 \%-25.0 \%)$, and non-pitting edema $(2.8 \%-6.9 \%)$. Chronic arsenic toxicity may cause multi-organ pathologies and for which arsenicosis patients may also be associated with complications. Complications like Bowen's disease, skin cancer, lung cancer, peripheral neuropathy, diabetes mellitus, hypertension and other cardiovascular diseases, chronic cough, asthma, peripheral vascular disease, gangrene, non-pitting edema, and hepatopathy have been reported in arsenic-exposed Bangladeshi population. ${ }^{3,15,21,22,29-31}$ Other reported adverse effects associated with chronic exposure to arsenic through drinking water in Bangladesh include adverse pregnancy outcomes (such as increased stillbirth, premature birth, low birth weight, and abortion) and decreased intelligence quotient (IQ) among the children. ${ }^{15,21,31-36}$

Regarding mortality, studies revealed an association of mortality with increased exposure to arsenic through drinking water. ${ }^{34,37}$ It has been reported that about $5.6 \%$ of the deaths in Bangladesh was attributable to arsenic exposure at levels that currently exist in the country. ${ }^{1,34}$ Besides, non-accidental death, cause-specific death rate estimation revealed that 1 in 16 cancer deaths, 1 in 36 cardiovascular disease deaths, and 1 in 19 deaths from infectious diseases among the arsenicexposed population are attributable to arsenic exposure. It has been estimated that as many as 1 in 100 additional cancer deaths may occur due to lifetime exposure to drinking arsenic-contaminated water containing $0.05 \mathrm{mg} / \mathrm{L}$. For the arsenic-exposed population of Bangladesh, mortality risks of lung cancer have been estimated to be 159.1/100,000 among males and 23.1/100,000 among females. ${ }^{34,38,39}$ The overall lifetime excess risk of mortality from liver, bladder, and lung cancers combined has been estimated to be 198.3 for males and 53.8 for females, and on average, irrespective of gender, the lifetime excess risk of mortality was 126.1 per 100,000 population. ${ }^{40,41}$ An estimation based on 9,136 deaths due to arsenic-related disease per year in the population exposed to arsenic through drinking water at a concentration more than $0.05 \mathrm{mg} / \mathrm{L}$ revealed that arsenic-related diseases constitute $0.3 \%$ of the total burden of diseases in Bangladesh. ${ }^{42}$

\section{Management of arsenicosis patients}

There is no specific medicine available for the treatment of arsenicosis. Cessation of further exposure to arsenic by stopping consumption of arsenic-contaminated water both for drinking and cooking purpose and to use arsenic-safe water for both the drinking and cooking purpose are the main management strategies for arsenicosis patients in Bangladesh.
In addition, arsenicosis patients are advised to take locally available protein and vitamin A, E, C rich food. The patients are also advised to take vitamin $\mathrm{A}$ (beta-carotene), E, and C as a medicinal supplement, and to apply keratolytic ointment to remove keratotic lesions of palm and sole. These management measures are found to be helpful in the early recovery of mild and moderate arsenicosis patients. But recovery is difficult in severe arsenicosis cases or in cases with complications. ${ }^{22,43-45}$ In Bangladesh, several studies have been carried out to assess different treatment regimens for arsenicosis patient management. Patients treated with spirulina, selenium, or folic acid showed a little improvement. However, vitamin $\mathrm{A}$ ( $\beta$-carotene), $\mathrm{E}$, and $\mathrm{C}$ regimen still is a commonly practised management for arsenicosis patients. ${ }^{43-46}$ DGHS supplies vitamin A, E, C to Upazilla Health Complexes for the management of arsenicosis patients, free of cost. In addition, DGHS has undertaken a number of programs which are community awareness raising regarding arsenic and safe water option; capacity building of the health professionals, management of arsenicosis patients; research and development; and cooperation and coordination with government and non-government organizations with an aim to reduce the suffering of the arsenicosis patients through early identification and provision of management as well as prevention of complications, particularly the cancer. ${ }^{24,25}$

Consumption of arsenic-safe water is the mainstay both for prevention of exposure to arsenic and management of arsenicosis. To meet this, in 1998, several programs had been undertaken to provide different types of arsenic-safe water options in the arsenic-affected areas of Bangladesh. Till 2005, a total of 106,939 alternate safe water options were provided throughout the country by the government and different national and international organizations, which covered about $38 \%$ population of arsenic-affected areas. The safe options included 74,808 DTWs, 13,324 rainwater harvesters, 6,268 DWs, 5,080 slow sand filters, 3,771 arsenic iron removal filters, and 3,521 pond sand filters (PSFs). ${ }^{14,25}$ In the following years, the installation of arsenic-safe water options increased by many folds and, by 2009 , about 692,488 different types of arsenic-safe water options were in place in arsenic-contaminated areas covering about $54.4 \%$ of the population. Among the options, more than two-thirds (72.6\%) were arsenic-safe tubewells. Other common safe options were DTW (23.8\%), DW (1.3\%), shallow shrouded tubewell $(1.2 \%)$, and PSF $(0.05 \%)$. But, it has been reported that onethird of these arsenic-safe water options are not being used by the households who have access to these options and at risk of exposure to arsenic-contaminated water. ${ }^{23,25,47,48}$ 


\section{Discussion}

To face the arsenic contamination problem in Bangladesh, government took many initiatives since the identification of arsenic contamination in the tubewell water in 1993. Initially, government formed a committee; the title of the committee was "Committee for Reviewing the Situation of Arsenic in Drinking Water in Bangladesh." The objective of the committee was to conduct fact-finding surveys with the aim to explore the extent of arsenic contamination problem and to find out if the exposed population was suffering from arsenic toxicity. Primarily, it was believed that arsenic contamination would be limited in western bordering districts of Bangladesh, particularly in Gangetic Delta region. With the progress of fact-finding, arsenic contamination of tubewells in various parts of Bangladesh surfaced. Considering the vast problem of arsenic contamination, government, in 1996, declared arsenic contamination in groundwater as a national problem and formed three national committees namely "National Steering Committee," "Arsenic Technical Committee," and "Scientific Research Committee" with an aim to undertake specific and appropriate activities to face and mitigate the arsenic contamination problem in Bangladesh. To undertake mitigation interventions in terms of arsenic-safe water supply, identification and management of arsenicosis patients, and public awareness, three technical working groups were formed. Initially, two projects were implemented throughout the country; one project was on testing arsenic in tubewells and supply of alternate arsenic-safe water and another one on the identification of arsenicosis case and their management and public awareness regarding arsenic contamination. ${ }^{22,49}$

To explore the extent of arsenic contamination problem as quickly as possible, Bangladesh government decided to test arsenic in tubewell water throughout the country using arsenic field test kit. The screening for arsenic in tubewells water was initiated in 1996, and up to 1999, water from 51,000 tubewells was tested for arsenic. In 1999, government formulated Nationwide Communication Strategies with a goal to raise the awareness of the people about the consequences of consuming arsenic through contaminated tubewell water and its economic implications, and to induce behavioral change for expediting the use of arsenic-safe water options. Government organized training programs on arsenic issues for the medical doctor, nurses, and health auxiliaries to develop a network of arsenic activities from the periphery to the central level. Personnel from national and international NGOs were also involved in the training programs. Considering the magnitude of arsenic contamination problem, government adopted short-term and long-term strategies. The short-term strategies were related to ongoing activities and the activities to be undertaken in near future. The long-term strategies were to develop sustainable safe water options particularly using surface water, to avoid further arsenic contamination of groundwater and to reduce or prevent the long-term consequences in arsenic-exposed population and to undertake researches. . $^{12,49-51}$

To cope the arsenic contamination situation, a comprehensive approach for arsenic-safe water supply, a project namely Bangladesh Arsenic Mitigation Water Supply Project (BAMWSP), was initiated by the government in 1998 . The BAMWASP conducted a blanket screening of nearly 5 million tubewells nationwide between 2000 and 2003 for detection of arsenic contamination. The screening program revealed that $29.1 \%$ of the of examined tubewells yielded arsenic-contaminated water containing arsenic at levels greater than the Bangladeshi standard of arsenic in drinking water $(0.05 \mathrm{mg} / \mathrm{L})$. During screening, the tubewells which were found to be arsenic contaminated were painted red (3.5 million) and the non-contaminated tubewells were painted green so that people could easily recognize the contaminated tubewells. ${ }^{52,53}$

In 2004, the government formulated National Policy for Arsenic Mitigation (NPAM) to confront the "groundwater arsenic problem," on the basis of which Arsenic Policy Support Unit (APSU) and Implementation Plan for Arsenic Mitigation (IPAM) guided by a national committee were formed. APSU was set up with an objective to support coordination in addressing arsenic contamination situation; supporting research and training; and supporting stakeholders in promoting effective and sustainable arsenic mitigation. The IPAM was formulated to address the arsenic contamination through a multisectoral approach. This was a framework plan for the related sectors with short-term, mid-term, and long-term responses. In the national policy, the main approaches that were recommended for the provision of arsenic-safe domestic water supply were:

1. Awareness raising in rural areas to expedite tubewell switching; promotion of the use of confirmed arsenicsafe tubewells (green marked) for drinking purposes, or promotion of the use of pond sand-filtered water for drinking purposes

2. Provision of arsenic-removal devices at household or community levels where no arsenic-safe tubewells were found

3. Installation of DTWs in the coastal zone where arsenicsafe tubewell water is unfit for drinking due to high salinity levels 
4. Construction of the piped water-supply system from arsenic-safe sources such as deep groundwater or treated surface water for urban and rural multi-village centers

5. Assessment of arsenic problems, arsenicosis patient identification, and estimation of arsenic level in the water, soil, farm, and livestock.

The national policy was made also to guide the National Water Policy 1998; however, National Water Policy was revised in 2013 giving much emphasis on sustainable safe water options and guidance for the management of various water resources by all concerned governmental and nongovernmental agencies including the private users. For this purpose, in the policy, indications and special importance have been given on promotion of efficient and socially responsible water use; delineation of public and private responsibilities, obligations, and accountability including cost sharing and cost recovery; decentralization of water management activities where appropriate; and ensuring community participation..$^{50,51,53,54}$

\section{Safe water options}

To prevent the consequences of chronic exposure to arsenic through drinking water, consumption of arsenic-safe water is a must. NPAM provided a guideline for mitigating the effect of arsenic on people and environment in a realistic and sustainable way. The policy statement of NPAM is "Access to safe water for drinking and cooking shall be ensured through the implementation of alternative water supply options in all arsenic affected areas. All arsenicosis cases shall be diagnosed and brought under an effective management system. Impact of arsenic on the agricultural environment shall be assessed and addressed." NPAM have recommended a number of technical options as a source of water such as dug wells (DWs), PSFs, and rainwater harvesting. The policy preferred the use of surface water rather than the use of groundwater and recommended the use of locally appropriate alternative option to provide safe water. Neither groundwater nor the surface water can be chosen as a source of water without examination. Selection of technology should be on the basis of some criteria such as the cost of installation, potential to supply safe water, availability of water around the year, userfriendliness, operation and maintenance cost, and potential for community participation. ${ }^{25,54}$

The initial screening of tubewells for arsenic reported that $29 \%$ of the tested tubewells were arsenic contaminated. After 4 years of the initial screening, the nationwide blanket survey of almost 5 million tubewells by BAMWASP reported a similar proportion (29.1\%) of tubewells to be arsenic contaminated. However, in 2009, the sample survey for arsenic in household water throughout the country reported that $12.6 \%$ of examined sample water was arsenic contaminated. In 2009, the Multiple Indicator Cluster Survey (MICS) which examined 13,301 household water samples for arsenic throughout the country reported that $12.6 \%$ of examined samples of water were arsenic contaminated. This was an indication that there was an increase in the access of the people to arsenic-safe water sources. However, after 4 years, in 2013, the MICS reported an almost similar (12.4\%) proportion of household water samples $(13,800)$ were arsenic contaminated, which reflected that the access to the arsenic-safe water option did not increase since 2009. ${ }^{14,23,55}$ From 1998, a varieties of alternative options - such as rainwater harvester, DW, PSF, arsenic iron removal plant (AIRP), and DTW, were being installed in arsenic affected areas as a means of emergency arsenic mitigation measure supported by various national and international organizations' agencies. Till 2005, the alternate arsenic-safe water options installed throughout the country by different stakeholders covered more than one-third (38\%) of the population of arsenic-affected areas. ${ }^{14,23.25,52}$ Since then, the installation of arsenic-safe water options had been found to increase in many folds and, till 2009, different types of arsenic-safe water options were accessible to the people in arsenic-contaminated areas covering $54.4 \%$ of the population. However, a large number of safe water options were being installed throughout the country with an aim to combat the groundwater arsenic contamination in Bangladesh as well as to reduce the arsenic exposure to the people by establishing a sustainable arsenic-safe water system. But, it has been reported that one-third of these arsenic-safe water options are not in use or abandoned. The main reasons were the mechanical or technical failure of the options or options are reported to be arsenic contaminated. Other reasons revealed were lack of maintenance, not repaired, and the negative human behavior such as bad taste and odor, far distance, lack of social acceptability, lack of community participation, ownership ego, and misconception of no damage of health by drinking arsenic-contaminated tubewell water. ${ }^{23,25,48,52,53,56}$

Considering the above situation, to establish a sustainable arsenic-safe water system, an NGO in Jeshore took initiatives to ensure access of all the people to the safe water options. The main objective of the initiative was to ensure the availability of regular technical support for the safe water options. For that purpose, a local person was provided with some technical training on different water options and was appointed as a "Pani Paridrashak" (Water Inspector), 
who was responsible for regular monitoring, maintenance, repair, and periodical water quality test. This program has been established through the active community participation and support of the local government (Union Parishad). The community people formed a committee, selected the person for technical support, and contributed some money monthly to meet the expenditure for maintenance and repair of the options, and salary of the "Pani Paridrashak." Now the community has attained the ability to install, repair, and maintain safe water options by themselves. This program has been conducted by Asia Arsenic Network (AAN) since 2013 and has been reported to be successful to assure the safe drinking water and a steady supply of water to the community people till now. In the meantime, it is included in the Implementation Plan of Arsenic Mitigation for Water Supply (IPAM-WS) and a number of organizations implementing similar programs in their working areas reported to be successful in establishing a sustainable arsenic-safe water system. However, to prevent the exposure to arsenic through other sources, a holistic approach has been undertaken in the IPAM by including three other sectors which are Health (IPAM-H), Agriculture (IPAM-Ag), and Water Resources (IPAM-WR). These sectors develop their own implementation plan for the successful implementation of arsenic mitigation programs in Bangladesh. ${ }^{56-58}$

\section{Health impact}

Consuming arsenic-contaminated tubewell water for a long time may cause chronic toxicity in human health. Arsenicosis is an illness that develops due to chronic low-dose arsenic exposure and is prevalent in arsenic-contaminated areas of Bangladesh. The arsenicosis patient is diagnosed on the basis of WHO arsenicosis case diagnosis protocol which mainly considers the characteristics of skin manifestations and arsenic exposure history. The arsenic-exposed individuals even when consuming the same level of arsenic, all do not develop arsenicosis; the manifestation of arsenicosis possibly depends upon various factors including genetic predisposition. In Bangladesh, a large number of people are consuming arsenic-contaminated tubewell water but a few of them are reported to be suffering arsenicosis; the prevalence of arsenicosis in arsenic-affected areas has been reported to be 45.1 cases in $100,000(0.05 \%)$ exposed population. ${ }^{23}$ So far, the arsenicosis patients identified $(65,910)$ by DGHS throughout the country is not a big number, which might be the tip of the iceberg. Though DGHS has undertaken a number of measures to avoid or reduce underreporting of arsenicosis cases, there remains scope of underreporting during executing the identification program especially due to the ignorance of the people participating in the activities. ${ }^{24,28}$

It is known that long-term exposure to arsenic may cause or influence the occurrence of multi-organ pathologies especially cancer without the development of the classical signs of arsenicosis. ${ }^{39}$ In Bangladesh, as arsenicosis case diagnosis is based on the presence of characteristic skin lesion, it is likely that the size of the arsenic-induced health problem is being understated. Therefore, people who are chronically exposed to arsenic through consuming arsenic-contaminated water should be monitored regularly for early detection of any illness or pathology attributable to chronic arsenic toxicity. DGHS should give attention to this problem and undertake special measures for regular monitoring of the arsenic-exposed population. If the effective activities are not taken to monitor the exposed population, the number of cancer cases may overwhelmingly increase. However, it has been reported that the current activities of DGHS relating to arsenic contamination is not in place, healthcare personnel are not helping the arsenic-exposed personnel in seeking medical attention, medical officers are not giving special attention to the arsenicosis patients, arsenicosis patients are discouraged in seeking treatment from the health complex, patients are often not being provided with any antioxidants and keratolytic ointment, and none the less periodic home visits for identification of arsenicosis patients has become none existent. ${ }^{59}$

The management of arsenicosis is a big public health challenge as there is no specific treatment or management for the arsenicosis patients. The mainstay of arsenicosis treatment is to stop further exposure to arsenic through drinking and cooking with arsenic-contaminated water. Studies have shown a considerable improvement of mild and moderate cases by stopping further intake of arsenic-contaminated water and taking protein-rich food and vitamin A, E, and C supplementation. Another study has demonstrated an improvement of arsenicosis patients to some extent when spirulina is taken in high doses. DGHS provided vitamin A, E, and C and some other antioxidants and keratolytic ointment for arsenicosis patient management through its healthcare facilities free of cost. However, it has been reported that currently the supply of vitamin A, E, and C supplementation by DGHS is often irregular. ${ }^{22,24,43-46}$

The curative treatment for arsenicosis which is practised currently does not show quick improvement if the instructions provided by the physician are not followed by the patients properly. For an effective treatment, long-term case management, even more than years, is often required; in addition, 
confidence, patience, and adherence of the patients to the management protocol are also essential for a successful management. On the other hand, some arsenicosis patients do not seek treatment for their illness in early stage rather they seek treatment when arsenicosis becomes severe and complicated, and at this stage, the successful treatment is almost impossible. Thus, all these issues may cause noncompliance of the patient about arsenicosis treatment and may develop misconceptions regarding arsenicosis and its management.

Arsenic contamination, arsenicosis, and its complications constitute a substantial public health burden. Although the provision of arsenic-safe water supply is an important factor for the effective management of arsenicosis which is not under the purview of the DGHS activities, still DGHS can take lead in developing of effective intersectoral cooperation and coordination particularly for arsenic-safe water options. To increase the access to the health care for arsenic victims, adequate facilities and services should be ensured. On the other hand, the motivational program to raise awareness should be strengthened. For easy accessibility to the treatment facilities, services of the community clinic can be utilized. To provide proper care and treatment of complicated cases, a referral system can be established from community clinic to tertiary level of health care and this service should be under the guidance and support of the local healthcare professional. For follow-up and monitoring of arsenicosis cases, a digital information system may be developed and utilized. The arsenic-exposed population having no arsenicosis should be monitored for early detection of any health effect attributable to chronic arsenic toxicity, especially cancer, for which yearly screening programs can also be organized in arsenic-affected areas. However, in the current situation of healthcare services, it appears that the arsenicosis patients are not getting adequate and proper treatment and the chronically arsenic-exposed populations are not getting proper attention, which thus can make the mitigation of arsenic contamination problem more difficult. To overcome this crisis, healthcare services need to be organized properly with an aim to give more emphasis on arsenic contamination problem and develop effective strategies and actions so that a sustainable mitigation of arsenic crisis can be achieved.

The problem of arsenic contamination of groundwater is a big public health challenge, and to mitigate the arsenic contamination problem, a multi-sectoral approach needs to be adopted. The challenges are: 1) providing safe drinking water in arsenic-affected areas through sustainable safe water options; 2) involving local government in regular monitoring of the drinking water sources and their maintenance; 3 ) providing proper management of the arsenicosis patients through an organized follow-up system including surveillance for complications; 4) regular monitoring of arsenicexposed population and taking action if any health effect attributable to chronic toxicity appears or detected; and 5) encourage research on groundwater arsenic contamination issues and remediation and effect of arsenic toxicity and their management.

\section{Conclusion and recommendation}

Arsenicosis due to arsenic contamination in drinking water is a major public health crisis in Bangladesh. Since the identification of arsenic-contaminated tubewells and arsenicosis patients, government and non-government organizations undertook several activities to stop the arsenic exposure through drinking water by providing alternate sources of arsenic-safe water, identification of arsenicosis patients and their management, and mass awareness programs. These activities could only bring about a little sustainable significant positive impact. The lagging of sustainable arsenic-safe water supply and effective arsenicosis management program is apparent, and surveillance for complications particularly cancers among arsenicosis patients and arsenic-exposed populations is lacking.

\section{Disclosure}

The authors report no conflicts of interest in this work.

\section{References}

1. Arsenic W.H.O. World Health Organization, February 15, 2018. Available from: http://www.who.int/news-room/fact-sheets/detail/arsenic. Accessed March 16, 2018.

2. Bagchi S. Arsenic threat reaching global dimensions. CMAJ. 2007;177(11):1344-1345.

3. Ahmad SA, Khan MH. Ground water arsenic contamination and its health effects in Bangladesh. In: Flora SJS, editor. Handbook of Arsenic Toxicology. USA: Academic Press Publishers; 2015:51-72.

4. Dhar RK, Biswas VK, Samanta S. Ground water calamity in Bangladesh. Current Sci. 1997;73(1):48-59.

5. Smith AH, Lingas EO, Rahman M. Contamination of drinking-water by arsenic in Bangladesh: a public health emergency. Bull World Health Organ. 2000;78(9):1093-1103.

6. Ahmad SA, Khan MH, Faruquee MH. Arsenicosis: Nutrition and Socioeconomic Factors. J Pre Soc Med. 2012;31(1-2):52-63.

7. NGOs Arsenic Information \& Support Unit (NAISU). Arsenic 2002 , An overview of arsenic issues and mitigation initiatives in Bangladesh. Available from: http://wilsonweb.physics.harvard.edu/arsenic/remediation/NAISU_2003.pdf. Accessed March 16, 2018.

8. BBS. Statistical Pocketbook of Bangladesh. Dhaka: Bangladesh Bureau of Statistics-2016; 2014.

9. MOEF. National Adaptation Programme of Action (NAPA). Ministry of Environment and Forest, Government of People's Republic of Bangladesh. Available from: https://unfccc.int/resource/docs/napa/ban01. pdf. Accessed March 16, 2018.

10. Islam S, Miah S. Rivers of Bangladesh. Asiatic Society of Bangladesh. 1st ed. Dhaka,. Vol. 8; 2003:430-441. 
11. Ahmad SA, Sayed MH, Khan MH, et al. Sociocultural aspects of arsenicosis in Bangladesh: community perspective. J Environ Sci Health A Tox Hazard Subst Environ Eng. 2007;42(12):1945-1958.

12. BGS and DPHE; Kinniburgh DG and Smedley PL. Arsenic Contamination of Ground Water in Bangladesh. . Vol. 1\&2. Keyworth: British Geological Survey; 2001.

13. Ahmed MF, Rahman MM. Water Supply and Sanitation, Rural and Low Income Urban Communities. Dhaka: ITN- BUET; 2000.

14. DPHEArsenic contamination and Mitigation in Bangladesh. Dept of Public Health Engineering (DPHE). Available from: https://www. dphe.gov.bd/index.php?option $=$ com_content $\&$ view $=$ article $\&$ id $=96 \&$ Itemid=104. Accessed March 10, 2018.

15. Yunus FM, Khan S, Chowdhury P, Milton AH, Hussain S, Rahman M. A Review of Groundwater Arsenic Contamination in Bangladesh: The Millennium Development Goal Era and Beyond. Int J Environ Res Public Health. 2016;13(2):215-218.

16. Ahmad SA. Human behavioural aspects of water use. J Preven Soc Med. 1999;2(4-9):60-62.

17. Islam M.S and Islam M.S. Arsenic Contamination In Groundwater In Bangladesh: An Environmental And Social Disaster. IWA Publishing. Available from: https://www.iwapublishing.com/news/arsenic-contamination-groundwater-bangladesh-environmental-and-social-disaster. Accessed March 18, 2018.

18. DPHE/BGS/MML. Groundwater Studies for Arsenic Contamination in Bangladesh. Phase I: Rapid Investigation Phase. UK: British Geological Survey and Mott MacDonald Ltd; 1999.

19. Md. Safiuddin, Safiuddin M, Shirazi SM, Yussof S. Arsenic contamination of groundwater in Bangladesh: A review. International Journal of the Physical Sciences. 2011;6(30):6791-6800. http://www.academicjournals. org/IJPS

20. Shankar S, Shanker U, Shikha, Shanka U S. Arsenic contamination of groundwater: a review of sources, prevalence, health risks, and strategies for mitigation. ScientificWorldJournal. 2014;2014:304524-18.

21. Ahmad SA, Sayed MH, Barua S, et al. Arsenic in drinking water and pregnancy outcomes. Environ Health Perspect. 2001;109(6):629-631.

22. Khan AW, Ahmad SA, Sayed M. Arsenic contamination in ground water and its effects on human health with particular reference to Bangladesh. J Pre Soc Med. 1997;16(1):65-73.

23. DPHE. Situation Analysis of Arsenic Mitigation. Dhaka: Department of Public Health Engineering; 2009-2010.

24. DGHS. Health Bulletin-2016. Dhaka: Directorate General of Health Services; 2016.

25. FAO, UNICEF, WHO and WSP. Towards an Arsenic Safe Environment. Dhaka: A joint publication of FAO, UNICEF, WHO and WSP; 2010.

26. Ahmad SA, Sayed MH, Faruquee MH, et al. Arsenicosis: sex differentials. J Prev Soc Med. 1999;18(1):35-40.

27. Misbahuddin M, Anjumanara LAK. Speciation of arsenic in rice and vegetables from arsenic exposed areas in Bangladesh. Dhaka: W.H.O Misbahuddin M, editor. Bangladesh: Applied research on arsenic in; 2007:43-52. http://www.un-bd.org/Docs/Publication/Applied\%20 research $\% 20$ on\%20arsenic\%20in\%20Bangladesh.Pdf.

28. WHO. A field guide for detection, management and surveillance of arsenicosis cases. Caussy D, editor. New Delhi: SEARO, WHO; 2005.

29. Ahmad SA, Sayed MHSU, Hadi SA, et al. Arsenicosis in a village in Bangladesh. Int J Environ Health Res. 1999;9(3):187-195.

30. Maidul AZM, Momin A, Akramullah SM, et al. Arsenical Keratosis (Chronic Arsenism. Bangladesh J Derma Venerol Leprol;13(1):1-4.

31. Sikder MS, Maidul AZN, Momin A. Clinical manifestation of chronic arsenic toxicity in Bangladesh-A 250 case study. Bangladesh J Derma Venerol Leprol. 1999;16(1):6-8.

32. Milton AH, Smith W, Rahman B, et al. Chronic arsenic exposure and adverse pregnancy outcomes in bangladesh. Epidemiology. 2005;16(1):82-86.

33. Kwok RK, Kaufmann RB, Jakariya M. Arsenic in drinking-water and reproductive health outcomes: a study of participants in the Bangladesh Integrated Nutrition Programme. J Health Popul Nutr. 2006;24(2):190-205.
34. Flanagan SV, Johnston RB, Zheng Y. Arsenic in tube well water in Bangladesh: health and economic impacts and implications for arsenic mitigation. Bull World Health Organ. 2012;90(11):839-846.

35. Akhtar N, Islam A, Mannan MA. Evaluation of Physical and Mental Development of Children of Arsenic Exposed Areas in Bangladesh. Misbahuddin M, editor. Dhaka: Applied Research on Arsenic inWHO; 2007:15-30

36. Nahar MN, Inaoka T, Fujimura M. A consecutive study on arsenic exposure and intelligence quotient (IQ) of children in Bangladesh. Environ Health Prev Med. 2014;19(3):194-199.

37. Sohel N, Persson LA, Rahman M, et al. Arsenic in drinking water and adult mortality: a population-based cohort study in rural Bangladesh. Epidemiology. 2009;20(6):824-830.

38. Chen Y, Graziano JH, Parvez F, et al. Arsenic exposure from drinking water and mortality from cardiovascular disease in Bangladesh: prospective cohort study. BMJ. 2011;342(d243):d2431.

39. Martinez VD, Vucic EA, Santos DDB. Gil L and Lam WL Arsenic Exposure and the Induction of Human Cancers. J Toxicol. 2011;2011; 431287431287.

40. Rao CV, Pal S, Mohammed A, et al. Biological effects and epidemiological consequences of arsenic exposure, and reagents that can ameliorate arsenic damage in vivo. Oncotarget. 2017;8(34): 57605-57621.

41. Chen Y, Ahsan H. Cancer Burden from Arsenic in Drinking Water in Bangladesh. Am J Public Health. 2004;94(5):741-744.

42. Lokuge KM, Smith W, Caldwell B, et al. The Effect of Arsenic Mitigation Interventions on Disease Burden in Bangladesh. Env Health Perspect. 2004;112(11):1172-1177.

43. Alam M, Hazari SKS, Alam A. Prevalence of skin cancer in chronic Arsenicosis in Chittagong Medical College Hospital. JCMCTA. 2010;21(1):23-29.

44. Ahmad SA, Faruquee MH, Sayed M, et al. Chronic Arsenicosis: Management by Vitamin A,E,C Regimen. J Prev Soc Med. 1998;17(1):19-26.

45. Khandker S, Dey RK, Islam A, Ahmad SA, Mahmud IA. Arsenic-safe drinking water and anti-oxidants for the management of Arsenicosis patients. Bangladesh J Pharmacol. 2006;1(2):42-50.

46. Sultana S, Hossian QZ, Pervin R. Socioeconomic Condition and Health Status of Chronic Arsenicosis Patients in Jessore, Bangladesh. Int $J$ Advan Nutr \& Health Sci. 2013;1(1):9-17and.

47. APSU. RiskAssessment of Arsenic Mitigation Options. Dhaka: Arsenic Policy Support Unit ITN-Bangladesh; 2005.

48. Inauen J, Hossain MM, Johnston RB, Mosler HJ. Acceptance and Use of Eight Arsenic-Safe Drinking Water Options in Bangladesh. PLoS ONE. 2013;80053640(1):e53640.

49. Khan AW, Ahmad SA. Arsenic in Drinking Water, Health Effects and Management, A Training Manual. Bangladesh: Department of Occupational \& Environmental Health, NIPSOM; 1997.

50. WB. Towards more Effective Operational Response: Arsenic Contamination of Groundwater in South and East Asian countries. Volume II Technical Report. The World Bank. Available from: http://siteresources. worldbank.org/INTSAREGTOPWATRES/Resources/ArsenicVolII_ PaperI.pdf. Accessed November 23, 2018.

51. MLGRD. National Policy for Arsenic Mitigation 2004. Ministry of Local Government, Rural Development and Co-operative. 2004. Available from: https://www.dphe.gov.bd/pdf/National-Policy-for-ArsenicMitigation-2004.pdf. Accessed March 26, 2018.

52. UNICEF. Arsenic Mitigation in Bangladesh. Dhaka: UNICEF; 2000.

53. Shafiquzzaman M, Azam MS, Mishima I, Nakajima J. Technical and Social Evaluation of Arsenic Mitigation in Rural Bangladesh. J Health Popul Nutr. 2009;27(5):674-683.

54. Arsenic Policy Support Unit (APSU). Selected papers on the social aspects of arsenic and arsenic mitigation in Bangladesh. Bangladesh. APSU; 2006. Available from: http://wilsonweb.physics.harvard.edu/ arsenic/references/selected_social_papers.pdf.

55. BBS and UNICEF Bangladesh Multiple Indicator Cluster Survey 2012-2013, ProgotirPathey: Final Report. Bangladesh Bureau of Statistics (BBS) and UNICEF Bangladesh, 2014, Dhaka, Bangladesh. 
56. LGD/JICA. Sustainable Arsenic Mitigation under Integrated Local Government System in Jessore. Dhaka, Bangladesh: Local Government Division (LGD), Ministry of Local Government, Rural Development, \& Cooperatives Japan International Cooperation Agency (JICA).

57. PSU. Development of implementation Plan of Arsenic Mitigation for Water Supply (IPAM-WS) Policy Support Uint, DPHE; 2015.

58. AAN/JICA. Model Building for safe water Supply service by local government institution final report. Dhaka: Asia Arsenic Network/Japan International Cooperation Agency; 2015.
59. Human Rights Watch. Nepotism and Neglect: The Failing Response to Arsenicin the Drinking Water of Bangladesh's Rural Poor. USA. Human Rights Watch Report; 2016. 2016. Available from: https://www.hrw. org/sites/default/files/report_pdf/bangladesh0416web_1.pdf. Accessed March 27, 2018.
Risk Management and Healthcare Policy

\section{Publish your work in this journal}

Risk Management and Healthcare Policy is an international, peer-reviewed open access journal focusing on all aspects of public health, policy, and preventative measures to promote good health and improve morbidity and mortality in the population. The journal welcomes submitted papers covering original research, basic science, clinical and epidemiological studies, reviews and evaluations, guidelines, expert opinion and commentary, case reports and extended reports. The manuscript management system is completely online and includes a very quick and fair peerreview system, which is all easy to use. Visit http://www.dovepress.com/ testimonials.php to read real quotes from published authors. 